\title{
UMA EXPERIÊNCIA SOBRE APROVEITAMENTO DE ESTUDOS
}

\author{
SÃO PAULO/SP MAIO/2018
}

\begin{abstract}
Marcus Danilo de Paula Stander - CRUZEIRO - marcus_stander@yahoo.com.br Carlos Fernando de Araújo Júnior - Cruzeiro do Sul Virtual - carlos.araujo@cruzeirodosul.edu.br Camila de Campos Silva - Cruzeiro do Sul Virtual - camila.campos@unicid.edu.br
\end{abstract}

Tipo: Relato de Experiência Inovadora (EI)

Categoria: Suporte e Serviços

Setor Educacional: EDUCAÇÃO SUPERIOR

\begin{abstract}
RESUMO
Este artigo aborda aspectos relevantes no Ensino à Distância no que se refere à aproveitamento de estudos e como as IES se organizam neste sentido. Foi realizado um estudo do desenvolvimento, atuação, organização e viabili-dade de um setor denominado Setor de Análise Curricular na IES em que faz parte. Para atingir o objetivo proposto, foi realizada pesquisa bibliográfica e quantitativa, além de utilizar informações advindas de banco de dados do pró-prio setor. Através dos dados coletados, foi possível avaliar que o interesse por parte dos alunos e candidatos a matrícula em aproveitar disciplinas já cursadas anteriormente têm aumentado, tornando-se útil a criação de um setor especia-lizado neste tipo de solicitação.
\end{abstract}

Palavras-chave: Aproveitamento de disciplinas, Gestão de setores da EAD, Ingresso de alunos, Segunda Graduação.

\section{AGRADECIMENTOS}

AGRADEÇO A PRÓ-REITORIA DA IES, AOS FUNCIONÁRIOS DO SETOR QUE CONTRIBUÍRAM COM O LEVANTAMENTO DE INFORMAÇÕES PARA A REALIZAÇÃO DESTE ARTIGO E AOS SETORES QUE FAZEM PARTE DO FLUXO DESTE PROCESSO DENTRO 


\section{Introdução}

O grupo Educacional a que este relato pertence possui atualmente cerca de 100.000 alunos de graduação a distância e desde 2012 vem ampliando seu portfólio de cursos nesta modalidade e ampliando as possibilidades de ofertas com aquisições de outras IES que ofereçam a modalidade a distância.

Em 2014, frente a necessidade do mercado e tendo como premissa que segundo Stander (2016, p.76), 22\% dos alunos EaD deste grupo educacional já concluiu outro curso de educação superior, e outra parcela dos alunos já iniciaram outro curso e não concluíram, a instituição teve a iniciativa de criar um setor específico para a realização de processos de aproveitamento de disciplinas cursadas em outras IES para a área de EaD.

Até este momento, estes pedidos de alunos eram atendidos pelos coordenadores dos seus respectivos cursos. Como as matrículas vinham crescendo exponencialmente e os coordenadores de curso não mais conseguiam dar vazão ao volume apresentado de pedidos, surgiu a ideia de criação de uma unidade que pudesse realizar este atendimento: o Setor de Análise Curricular, que foi constituído no ano de 2014 e gradualmente ganhou notoriedade no trabalho realizado nos processos de candidatos (Segunda Graduação e Transferências oriundas de outras IES) e alunos (Dispensas de Disciplinas e Transferências Internas). No início, funcionários administrativos recebiam apoio e orientação dos coordenadores de curso a fim de estabelecer quais eram as premissas para a realização dos aproveitamentos de disciplinas.

Tendo como base que parte dos alunos ingressantes na IES era de alunos de segunda graduação, este setor também foi desenvolvido com o objetivo de dar atendimento a esta demanda. Este relato foi restabelecido com os objetivos de: Apresentar o desenvolvimento do Setor de Análise Curricular; Discutir a organização do Setor de Análise Curricular; Apresentar como outras IES se organizam neste sentido; Discutir a viabilidade de implementação desta unidade.

\section{Desenvolvimento do Setor}

O Setor de Análise Curricular atua na IES realizando análises de documentações de alunos (históricos escolares, diplomas, conteúdos programáticos, entre outros) com o intuito de verificar a possibilidade de dispensa de disciplinas.

A demanda desse trabalho vem crescendo cada vez mais, em decorrência do interesse 
por parte dos alunos e candidatos a matrícula em não cursar novamente disciplinas que já foram cursadas em algum momento de suas vidas acadêmicas e tentar reduzir o tempo de conclusão de curso.

A análise realizada sobre as documentações recebidas é regida por alguns critérios institucionais e setoriais que incluem compatibilidade de conteúdo, documentos que atendam aos requisitos necessários, coerência nas solicitações dos alunos e averiguação das informações recebidas. No segundo ano de atuação do Setor de Análise Curricular (2015), foi registrado um crescimento de $177 \%$ em volume de processos, se comparado ao primeiro ano. No ano de 2016, o setor registrou um crescimento de $\mathbf{8 2} \%$ comparado ao ano de 2015 e em 2017 registrou $\mathbf{2 6 \%}$ de crescimento comparado a 2016.

Gráfico 1 - Evolução de Processos Tramitados

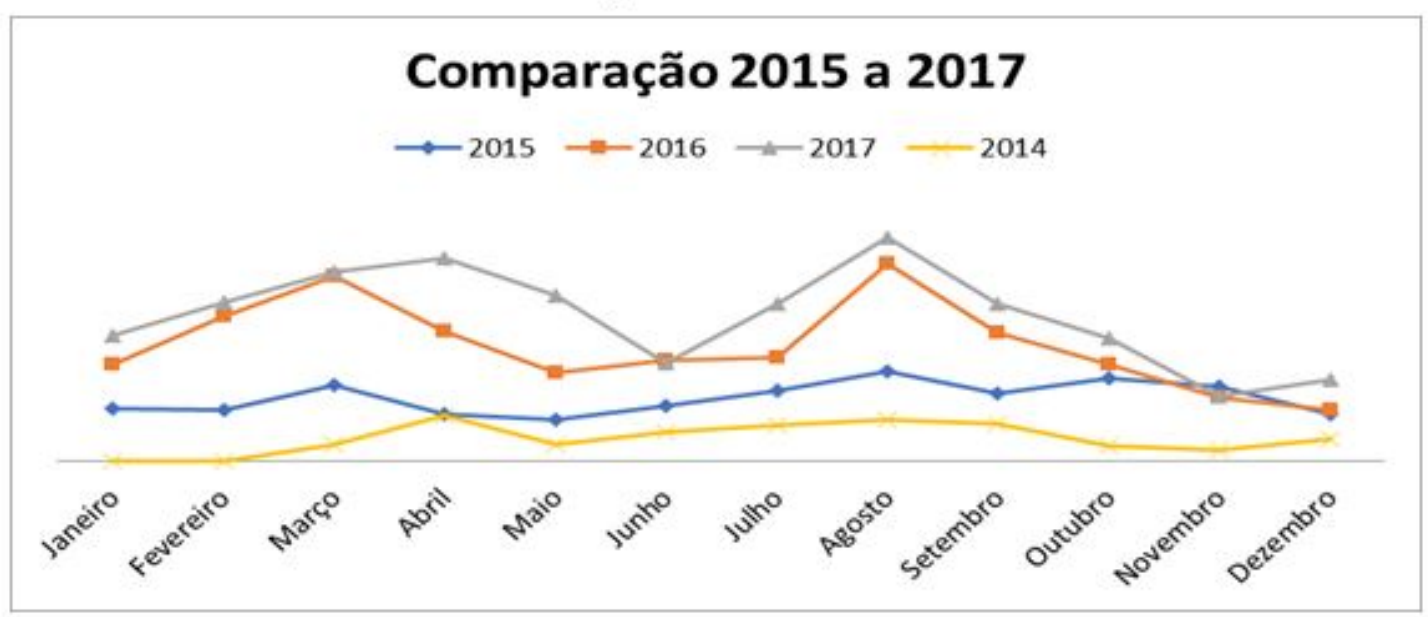

Fonte: Elaborado pelo Autor

Este volume de trabalho permitiu diretamente a realização de matrículas através dos processos realizados para análise de candidatos. Foi realizado um levantamento com os dados da própria IES e em 2017 foram possibilitadas pouco mais de 10.000 matrículas através dos processos realizados por este setor.

\section{Organização do Setor}

O cenário do estudo foi um grupo educacional de referência em Educação a Distância atualmente com cerca de 100.000 alunos. Seguindo as diretrizes determinadas pelas legislações pertinentes foi possível avaliar o crescimento do número de processos realizados pelo Setor de Análise Curricular. Segundo ANDREOLI and ROSSINI (2015, p.81) as organizações precisam de uma estrutura para organizar seus processos e procedimentos, o funcionamento desta estrutura dependerá de cada necessidade e de 
arranjos organizacionais estabelecidos pela organização.

Assim sendo, atualmente o Setor de Análise Curricular está dividido em dois subsetores: um subsetor denominado de Ingresso que responde pelos processos de candidatos de Segunda Graduação e Transferências de outras IES e outro subsetor denominado de Movimentações Acadêmicas, que cuida de processos de Dispensas de Disciplinas e Transferências Internas.

ANDREOLI and ROSSINI (2015, p. 108) afirmam que no processo de organizar uma instituição/empresa, existem diversos modelos, dentre eles a departamentalização por processo que neste caso, divide e agrupa as tarefas em torno do processo produtivo a que se destinam. Sendo processo produtivo uma série de atividades encadeadas e com o propósito de atingir um objetivo em comum.

Desta forma o setor utiliza de algumas técnicas e estratégias para facilitar seu trabalho e para ser mais assertivo no resultado das análises que são realizadas. "Foco no aluno" é uma das premissas presentes no dia a dia do setor, visto que atender às necessidades do aluno e satisfazê-lo com excelência é o objetivo principal do trabalho.

O setor conta com um banco de dados contendo "respostas padrão" que foram criadas a partir das solicitações mais comuns feitas pelos alunos e candidatos a matrícula. As respostas são agrupadas de acordo com o tipo de situação em que os documentos avaliados se encontram e como isso poderá impactar no resultado da análise. Como exemplo podemos citar a seguinte divisão de grupos de respostas feita pelo setor: pedidos deferidos e indeferidos, solicitação de documentos, documentos inválidos e orientações gerais.

Além disso, o setor possui um gerenciamento de documentos, que contém aproximadamente 130 modelos de históricos escolares de outras IES, para consultá-los quando for oportuno. O objetivo de possuir esses modelos é utilizá-los quando for detectada a necessidade de comparação entre históricos escolares da mesma IES para comprovar a autenticidade dos mesmos. Com esse banco de dados, o setor tem maior garantia de que históricos escolares de procedência duvidosa não sejam utilizados nas análises.

De acordo com ANDREOLI and ROSSINI (2015, p. 30), os sistemas são compostos por entrada (inputs), processamento, saídas (outputs) e subsistema de retroalimentação (feedback), além do objetivo e do ambiente em que atuam. Levando como base este conceito, o setor está atualmente sistematizado para que a experiência por hora 
recebida seja utilizada como referências para as demais decisões com a mesma situação. Tornando um sistema com entrada, processamento, saída e feedback, que neste caso pode ser considerado como a satisfação ou não de nosso aluno/candidato.

A estratégia criada pelo Setor de Análise Curricular para que os resultados das análises sejam coerentes e satisfatórios, é dividir a equipe também por área de formação. Os colaboradores que são graduados em cursos da área de negócios, são responsáveis pelas análises de alunos também destes cursos. O mesmo ocorre com os colaboradores graduados em licenciaturas e cursos na área de exatas.

Em virtude da diferença nos nomes das disciplinas pertencentes às matrizes curriculares dependendo de cada IES, foram criadas, com auxílio dos coordenadores de curso, planilhas que abrigam possíveis disciplinas que possuem nomes diferentes, mas apresentam o mesmo conteúdo. Assim, torna-se mais eficiente a associação de disciplinas e amplia as possibilidades de dispensar disciplinas já cursadas pelos alunos em outro momento de sua vida acadêmica.

Ao longo dos anos, o Setor de Análise Curricular foi reduzindo seus prazos médios de conclusão de processos a fim de se adequar a necessidade da IES, setor comercial e mercado. Em 2014, o prazo para conclusão dos processos era de 15 dias úteis, em 2015 de 9 dias úteis, em 2016 de 7 dias de úteis, em 2017 de 6 dias úteis e em 2018 de 4 dias úteis. A próxima etapa é transformar o tempo de resposta dos processos que envolvem candidatos em um dia útil.

Estas reduções foram sendo possibilitadas pelas melhorias implementadas pelos setores da IES e atualmente os processos ficam no Setor de Análise Curricular 1 dia útil, depois segue um fluxo para ser encerrado em 4 dias no total. Estas mudanças se fazem e fizeram necessárias devido as mudanças na forma como os sujeitos encaram o tempo na sociedade pós-moderna. BARRETO (2005, p. 118) afirma que "Ora, se o tempo para "ruminar" as informações não é mais o mesmo dos tempos das leituras tradicionais, continua, no entanto, a ser indispensável para a produção de sentidos".

Tudo isso corrobora com o fato que BARRETO (2005, p. 118) aponta como as alterações nos tempos sociais que resultam em outros tipos de relação entre os sujeitos e outro tipo de cultura, como a cibercultura, que é caracterizada pela rapidez e pela lógica utilitária que exige da leitura, mas que podemos estender a todas as áreas, a funcionalidade, da velocidade e da simultaneidade. 
A realização desta pesquisa se deu por pesquisa bibliográfica no que se refere aos conceitos teóricos utilizados como base na rotina de desenvolvimento do setor, e por pesquisa quantitativa realizada no mês de dezembro de 2017 através de contato com as IES consideradas como concorrentes da Instituição pesquisada a fim de obter os prazos dos processos relacionados.

Também consideramos as informações e banco de dados do próprio setor, desde a sua criação para que pudéssemos obter os dados reais do relato apresentado.

\section{Análise da Concorrência}

Movido pelo conceito de melhoria contínua apontado por YEN-TSANG et al (2010) como uma peça chave para manter a competitividade em um cenário dinâmico, em dezembro de 2017 o Setor de Análise Curricular realizou um levantamento de análise da concorrência e nesta análise foram listadas 14 IES consideradas como concorrentes.

Para YEN-TSANG et al (2010, p. 2), somente a inovação disruptiva não é suficiente para manter uma empresa competitiva ao longo do tempo, já que entre as sucessivas inovações disruptivas são necessárias as atividades de melhorias contínuas para combater a tendência natural da degradação do sistema. Em qualquer mercado, a concorrência é uma das maiores dificuldades dos gestores. A disputa pela confiança e o bolso dos consumidores é ainda maior em cenários econômicos turbulentos onde a população se torna mais restritiva com seus gastos.

Kotler (2000) in Lopes et al (2012), afirma que o objetivo maior do marketing é identificar e satisfazer as necessidades e desejos do cliente. Neste sentido torna-se vital conseguir novos clientes e manter os já existentes. Desta forma, afirma que o segundo objetivo só pode ser alcançado com ações de controle de qualidade de atendimento, de produção, da venda e mecanismos de feedback (com a finalidade de conhecer a percepção do cliente acerca dos serviços e produtos oferecidos pela empresa).

Assim, Souki (2006) in Lopes et al (2012), afirma ser vital monitorar os passos da concorrência, e para isso é importante planejar estratégias capazes de anular as vantagens competitivas impostas pela concorrência. Cada empresa constrói uma forma de concorrer com as demais integrantes do mesmo mercado e a forma como essa concorrência vai se delimitar vai depender na maioria das vezes fatores como: o tamanho e as perspectivas do mercado, a estrutura de cada empresa, a visão e os objetivos a serem alcançados. 
Com base nestes conceitos, o Setor de Análise Curricular realizou contato através de email, site, telefone e chat com estas 14 Instituições listadas como concorrentes do grupo estudado, a fim de obter informações de como se dão os processos que são realizados neste setor em outras instituições, com objetivo de conhecer as melhores práticas do mercado. O artigo técnico 17 do Sebrae lista três passos que apresentamos a seguir e que consideramos como premissa do trabalho realizado no setor discutido neste relato, conforme observado na Figura 1

Figura 1 - Análise da concorrência

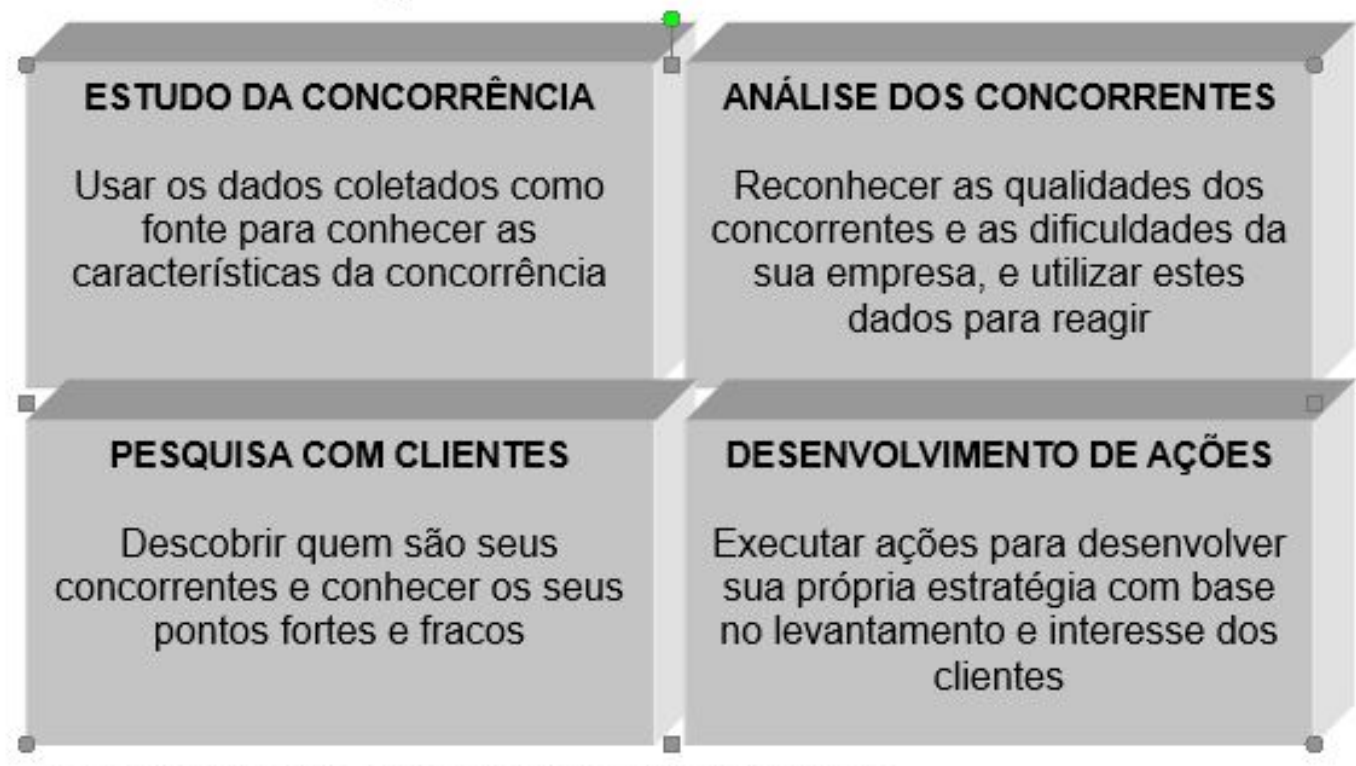

Fonte: Elaborado pelo autor com base no artigo técnico 17 do SEBRAE.

A pesquisa foi dividida em 3 situações diferentes: Segunda Graduação, Transferências Externas e Dispensas de Disciplinas para alunos regularmente matriculados. O trabalho foi realizado com diversas informações, mas para fins deste artigo iremos apresentar apenas o que se refere ao prazo de conclusão do processo.

Assim, no que se refere aos prazos apresentados pelo Setor de Análise Curricular, das 14 instituições pesquisadas, no processo de Segunda Graduação, 2 (14,30\%) não possuem este tipo de ingresso, $3(21,43 \%)$ não informaram o prazo para o pedido, 1 $(7,14 \%)$ dá resposta imediatamente, 2 (14,30\%) em 5 dias úteis, 2 (14,30\%) dão respostas em 30 dias úteis, 1 (7,14\%) dá resposta em 20 dias úteis, 2 (14,30\%) dão 
resposta em 15 dias úteis e 1 (7,14\%) dá resposta em 10 dias úteis.

De posse destes dados, é possível afirmar que 2 IES (14,30\%) possuem prazos próximos aos da IES pesquisada, e 1 (7,14\%) possui prazo melhor do que o da IES pesquisada, que possui atualmente 4 dias úteis.

No processo de Transferência Externa, 2 (14,30\%) não informaram o prazo para o pedido, 2 (14,30\%) dão resposta imediatamente, 2 (14,30\%) em 7 dias úteis, 1 (7,14\%) dá respostas em 5 dias úteis, 1 (7,14\%) dá resposta em 45 dias úteis, 1 (7,14\%) dá resposta em 20 dias úteis, 2 (14,30\%) dão resposta em 15 dias úteis e 3 (21,43\%) dão resposta em 10 dias úteis.

Assim, é possível afirmar que 1 IES (7,14\%) possui prazos próximos aos da IES pesquisada, e $2(14,30 \%)$ possuem prazos melhores do que o da IES pesquisada, que possui atualmente 4 dias úteis.

Por último, foram considerados os processos de Dispensas de Disciplinas de alunos regularmente matriculados e $5(35,71 \%)$ não informaram o prazo para o pedido, 2 $(14,30 \%)$ dão resposta imediatamente, 2 (14,30\%) em 10 dias úteis, 1 (7,14\%) dá resposta em 7 dias úteis, 1 (7,14\%) dá resposta em 60 dias úteis, 1 (7,14\%) dá resposta em 45 dias úteis, 1 (7,14\%) dá resposta em 30 dias úteis e 1 (7,14\%) dá resposta em 15 dias úteis.

Assim, é possível afirmar que 2 IES (14,30\%) possuem prazos melhores, e apenas 1 IES (7,14\%) que possui prazo mais próximo da instituição pesquisada, possui 7 dias úteis, já que nesta modalidade de pedido a IES pesquisada possui 5 dias úteis nas solicitações.

Também abstraímos uma consideração importante no que se refere a uma das concorrentes consideradas como diretas, pois a mesma não possui ingresso via Segunda Graduação e os prazos para alunos variam de 45 a 60 dias úteis para a realização de uma dispensa de quem está regularmente matriculado.

\section{Viabilidade}

De acordo com o que foi encontrado na pesquisa realizada, apenas 1 IES está organizada de forma semelhante ao que temos hoje no grupo estudado. Não foi possível obter dados para indicar o número de matrículas possibilitadas por este ingresso (Segunda Graduação) em cada IES pesquisada. No entanto, pelos dados apresentados 
é possível afirmar que a criação e instituição de um setor de aproveitamento de estudos para candidatos e alunos é viável do ponto de vista organizacional.

A criação de um setor de aproveitamento possibilita ao Coordenador de curso (pessoa responsável na maioria das IES) a realização de outras atividades pertinentes ao curso, dando a ele maior autonomia no planejamento de seu curso.

Além de possibilitar ao coordenador olhar melhor para o seu curso, este setor melhora o conhecimento da organização desta modalidade de ingresso, facilitando a análise de dados e resolução de eventuais problemas decorrentes do processo.

Para entendermos melhor do ponto de vista organizacional a viabilidade, basta estabelecermos um valor x para as matrículas e multiplicar pelo que foi possível matricular pelo trabalho deste setor.

Os funcionários contratados para estas atividades são administrativos e com um custo menor do que o de um coordenador de curso. A longo prazo, pode-se até pensar em redução de custos da organização com a implementação deste setor.

\section{Conclusões}

Com os dados levantados é possível afirmar que a instituição pesquisada está em condições de competir com o mercado no que tange aos prazos ofertados pelas IES concorrentes. A criação, o desenvolvimento e a autonomia conquistados pelo setor permitiu um aprimoramento dos processos de análise curricular dentro do EaD do grupo apresentado, de forma a conseguir maior viabilidade e visibilidade perante a administração da IES.

Este modelo utilizado pelo grupo é passível de implementação na gestão da educação superior e é viável do ponto de vista financeiro, tanto para os cursos presenciais como para a modalidade EaD.

Consideramos, com os dados obtidos, que é viável e tem se mostrado eficaz a criação, implementação e manutenção de uma área de aproveitamento de estudos. Já que podemos considerar que as IES na área de EaD precisam lidar com o desafio de compor o seu corpo de funcionários com poucos funcionários para lidar com cada vez mais alunos possibilitados pelo crescimento da EaD nos últimos anos.

\section{Referências}


STANDER, Marcus Danilo de Paula Stander. Infraestrutura dos polos de apoio presencial no SINAES: a percepção dos alunos de graduação a distância. -- São Paulo, 2016. $132 \mathrm{p}$.

ANDREOLI, Taís Pasquotto. ROSSINI, Fernando. Organização, Sistemas, Métodos [livro eletrônico]. Curitiba, InterSaberes, 2015. (Série Administração da Produção)

BARRETO, Angela Maria. Informação e Conhecimento na Era Digital. Transinformação vol.17 no.2 Campinas May/Aug. 2005 disponível em: http://www.scielo.br/pdf/tinf/v17n2/02.pdf

LOPES, Murilo Caetano Alves. BITTENCOURT, Jairo Alano de. OLIVEIRA, José Maria de. PEREIRA, Sebastião Eustáquio. CHAGAS, Paulo Cesar. As Ações de Marketing: Monitorando a Concorrência no Comércio Varejista de Materiais de Construção. Simpósio de Excelência em Gestão e Tecnologia. IX SEGeT 2012. Disponível em https://www.aedb.br/seget/arquivos/artigos12/35516507.pdf

SEBRAE. Artigo técnico 17 - Benchmarking e a análise da concorrência. Disponível em

https://m.sebrae.com.br/Sebrae/Portal\%20Sebrae/Anexos/artigos-tecnicos-panificacao/A rtigo\%20t\%C3\%A9cnico\%2017\%20-\%20Benchmarking\%20e\%20a\%20an\%C3\%A1lise \%20da\%20concorr\%C3\%AAncia.pdf

YEN-TSANG, Chen. CSILLAG, João Mário. JÚNIOR, Orlando Cattini. Melhoria contínua continua? Conceitos, Vertentes e Tendências. XXXIV Encontro da ANPAD. Rio de Janeiro/RJ - Setembro de 2010. Disponível em http://www.anpad.org.br/admin/pdf/gol1817.pdf 